\title{
Decoding network patterns for urban disaster prevention by comparing Neihu district of Taipei and Sumida district of Tokyo
}

\author{
Hung-Wen Chang $^{\mathrm{a}}$ and Wei-I Lee \\ Architecture Department, National Taiwan University of Science and Technology, Taiwan
}

\begin{abstract}
In this study, we performed routes network transport and emergency shelters capacity rate analyses to determine the accessibility and efficacy of urban patterns, and established a quantitative method for supplying priorities for actions of "Sendai Framework for Disaster Risk Reduction 2015-2030". By comparing two case studies, we used Space Syntax to develop two important indicators, Rn and CR, to present geographic information and hazard risk in a physical environment. This research also found potential function of $\mathrm{Rn}$ and decoded some patterns for urban planners or decision makers as follows : The most efficient configuration of the road network was not in the old areas of these two case studies because the several turns decreased the connectivity of the networks. And the CR indicator shown other findings about the quality of public facilities and services as follows : The service capacity of the emergency shelters was surveyed to indicate a higher correlation of residents population and preparedness security for disaster management. Therefore, with finding some risks that had not been encountered before, we addressed this proposed method is feasible and reliable to enhance the disaster preparedness for action regarding the 4th priority of "Sendai Framework for Disaster Risk Reduction 2015-2030".
\end{abstract}

\section{Approach to priorities for actions of "sendai framework for disaster risk reduction 2015-2030"}

The Sendai Framework for Disaster Risk Reduction 2015-2030 [1], which was formulated by the United Nations Office for Disaster Risk Reduction (UNISDR) after the Japan earthquake and tsunami in 2011, outlines seven clear targets and four priorities for action to prevent new and reduce existing disaster risks: (1) understanding disaster risk; (2) strengthening disaster risk governance to manage disaster risk; (3) investing in disaster reduction for resilience; and (4) enhancing disaster preparedness for effective response and to "Build Back Better" for recovery, rehabilitation, and reconstruction. The framework aims to substantially reduce disaster risk and potential loss of lives, livelihoods, and health, in addition to economic, physical, social, cultural, and environmental assets of persons, businesses, communities, and countries. The 4th priority for action is related to urban planning, prevention plans, and city governance (Table 1). An increased disaster risk indicates a need to strengthen disaster preparedness, take action in anticipation of events, and ensure that facilities are in place for effective

\footnotetext{
${ }^{a}$ Corresponding author : ai3098@gmail.com
} 
response and recovery in all phases of a disaster, including through integrating disaster risk reduction with development measures. Thus, the vulnerabilities arising from a disaster can be managed by reducing the risk of disasters (Figure 1).

Table 1. The relationship between priorities for action of Sendai Framework for Disaster Risk Reduction 20152030 and disaster management phase.

\begin{tabular}{cl}
\hline Priorities & \multicolumn{1}{c}{ Action } \\
\hline 1 & Understanding disaster risk \\
\hline 2 & $\begin{array}{l}\text { Strengthening disaster risk } \\
\text { governance to manage disaster } \\
\text { risk }\end{array}$ \\
\hline 4 & $\begin{array}{l}\text { Investing in disaster risk } \\
\text { reduction for resilience } \\
\text { Enhancing disaster preparedness } \\
\text { "Build Back Better" in recovery, } \\
\text { rehabilitation and reconstruction }\end{array}$ \\
\hline Recovery
\end{tabular}

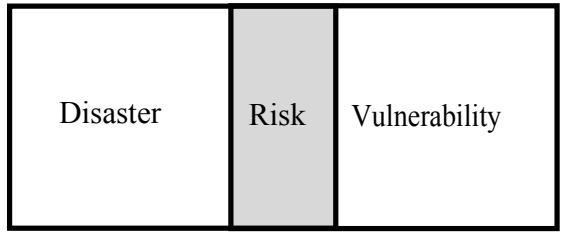

Figure 1. The role of prevention plans and urban planning in risk reduce.

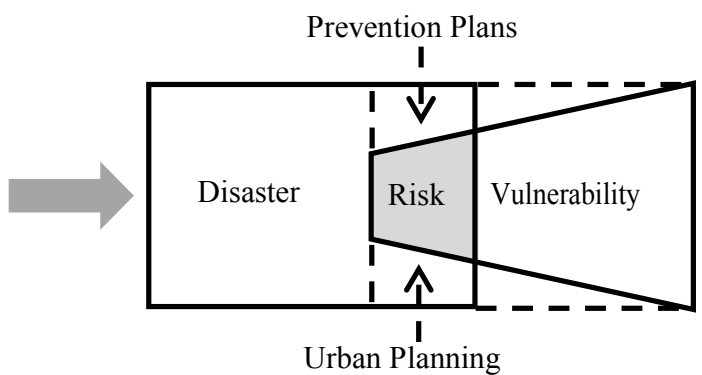

\section{Rapid diagnostic tests for urban resilience and literature review}

Coordination of public infrastructure is an integral part of any town and country planning process, and aims to provide unlimited uptime of all systems, enabling the fulfilment of basic needs during disaster response, threat to public safety, damage or even destruction of the surrounding buildings. Jetel has described approval of land use plans, regulatory plans and decision making using the concept of disaster prevention as an effective strategy for city governance [2]. A major task in city governance is resource allocation. To understand the dangerous properties in high-risk areas and improve the evacuation equipment, enhancing the ability to respond to disasters is critical [3]. David Alexander [4] (Figure 2) and Wei-I Lee [5-7] reported the need to evaluate urban disaster prevention strategies under given circumstances. They also expressed the need to designate routes and evacuation shelters. The former should guide the evacuees away from the source of danger. This paper investigates the relationship between the emergency infrastructure for urban disaster prevention and priority 4 of the Sendai framework (Table 2) and reports that evacuation routes and shelters are the most important infrastructure in urban disaster prevention, and can help in saving a large number of lives. 
Table 2. The relationship between the emergency infrastructure of urban disaster prevention and 4th priority for action of Sendai Framework for Disaster Risk Reduction 2015-2030.

\begin{tabular}{|c|c|c|c|c|c|c|}
\hline $\begin{array}{c}\text { National and local } \\
\text { levels }\end{array}$ & & & Emergen & Infrastructc & & \\
\hline Item & $\begin{array}{c}\text { Evacuation } \\
\text { Roads }\end{array}$ & Shelters & $\begin{array}{c}\text { Fire } \\
\text { Stations }\end{array}$ & Hospitals & $\begin{array}{c}\text { Relief } \\
\text { Supplies }\end{array}$ & $\begin{array}{c}\text { Police } \\
\text { Stations }\end{array}$ \\
\hline Achievement -1 & O & O & 0 & O & O & O \\
\hline Achievement -2 & & & 0 & & & \\
\hline Achievement -3 & 0 & & 0 & 0 & & 0 \\
\hline Achievement -4 & & 0 & & & & \\
\hline Achievement -5 & O & 0 & & & 0 & \\
\hline Achievement -6 & 0 & 0 & & & & \\
\hline Achievement -7 & O & 0 & & & & \\
\hline Achievement -8 & O & O & & & O & \\
\hline Achievement -9 & & & & & & O \\
\hline Achievement -10 & O & O & & & & \\
\hline Achievement -11 & 0 & & & & & \\
\hline Achievement -12 & 0 & 0 & 0 & 0 & & 0 \\
\hline Achievement -13 & 0 & 0 & & & & \\
\hline Achievement -14 & & 0 & & 0 & & \\
\hline Achievement -15 & & 0 & & 0 & 0 & \\
\hline Achievement -16 & & & 0 & & & 0 \\
\hline O:selected Sum & 10 & 11 & 5 & 5 & 4 & 5 \\
\hline
\end{tabular}
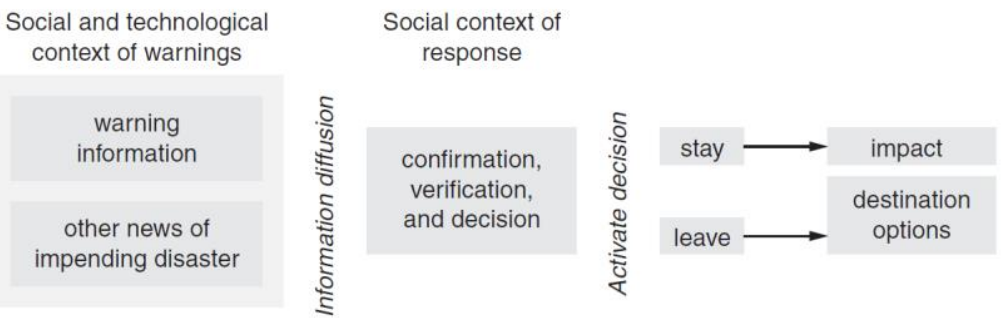

Figure 2. Evacuation plans have be made under given circumstances.(Reference from David Alexander's Principles in Emergency Planning and Management)

The details of achievements regarding the 4th priority of the Sendai Framework for Disaster Risk Reduction are as follows:

1. To update disaster preparedness and contingency policies, plans, and programs.

2. People-centric multihazard early warning systems, and disaster risk and emergency communication mechanisms.

3. Resilience of transportation and telecommunication infrastructure, educational facilities, and hospitals.

4. To establish community centers for the promotion of public awareness.

5. To establish or strengthen funding mechanisms and procedures for relief assistance and planning.

6. To train the existing workforce and voluntary workers to ensure better response in emergencies. 
7. To ensure the continuity of operations and planning, including social and economic recovery, and basic services in the post-disaster phase.

8. To ensure rapid and effective response to disasters and resulting displacement, including access to safe shelters, essential food, and nonfood relief supplies.

9. To promote the cooperation of diverse institutions, multiple authorities, and related stakeholders at all levels.

10. To develop capacities for reducing disaster risk in the short, medium, and long term, such as by land use planning and improvement of structural standards.

11. To develop guidelines for the preparedness of disaster reconstruction, such as for land use planning and improvement of structural standards.

12. To consider the relocation of public facilities and infrastructure to appropriate areas outside the risk range.

13. To improve the ability of local authorities to evacuate persons living in disaster-prone areas.

14. To establish mechanisms of case registry and databases of mortality to improve the prevention of morbidity.

15. To enhance recovery schemes to provide psychosocial support and mental health services to all people in need.

16. To review and strengthen the national laws and procedures on international cooperation based on DRR guidelines.

A problem in the achievement of the "Sendai Framework for Disaster Risk Reduction 2015-2030" is the fact that no evaluation criteria are available. In this paper, an indicator to understand the risk levels in city environment is thus developed. The paper also contributes to the trend of urban resilience and risk management. Some major safety performance evaluation approaches are identified, which include expectation function, risk assessment, statistical quality control, price deflation, engineering economic factors, system analysis, artificial intelligence, and systems theory [8]. Based on these approaches, quantitative and qualitative models are proposed. However, the quantitative models focus on measuring indicators such as frequency, severity, percentages, relative weight, and economic gains and losses of the safety program. Moreover, an evaluation procedure for the evacuation routes and shelters is proposed for use by urban planners or the government.

Jianan Liu reported that an urban spatial structure is a methodology to understand land use and human behavior. Moreover, he proposed to use space syntax and geographic information systems [9]. In this study, a network of evacuation routes was evaluated by using space syntax.

Chang Hsueh Sheng and Liao Chin Hsien also used space syntax to study the relationship between the efficiency of a path and the location of shelters [10]. Moreover, they investigated the challenges in the planning of emergency shelter locations during disaster events. Previous research has been hindered by the inability to consider both the service capacity and mobility of the road network and by the lack of a method for assigning evacuees to emergency shelters after a disaster causes road closures. Therefore, they proposed considering the network and limited scope of serviceability of the emergency shelters. This paper analyzed the advantages of examining the service value of shelters in our case study.

Liao Chin Hsien and Chang Hsueh Sheng applied and aggregated landslide points, land use data, and socioeconomic indicators integrated with a mapping method to analyze the relationship between spatial structures and spatial patterns of disaggregate and aggregate levels in natural hazard areas [11]. Moreover, they sorted out regional maps to present the hazard locations. In this study, space syntax was used to evaluate the evacuation routes and capacity rate to examine the shelters' service value, and feedback to mapping the high-risk areas or low-risk areas. This paper thus proposes a tool for the 4th priority for action of the "Sendai Framework for Disaster Risk Reduction 2015-2030."

\section{Methodology}

The disaster prevention plans should be evaluated through spatial structure analysis and location configuration assessment to offer quantitative information for decision making. This paper presents a 
process to set up a frame(Figure 3) to rethink the arrangement of infrastructure and relief supplies. Moreover, it provides a tool as a spatial analytical method to understand the risk of a disaster for developing a new inspection system to manage disaster risk and urban resilience. The procedure and indicators are as follows:

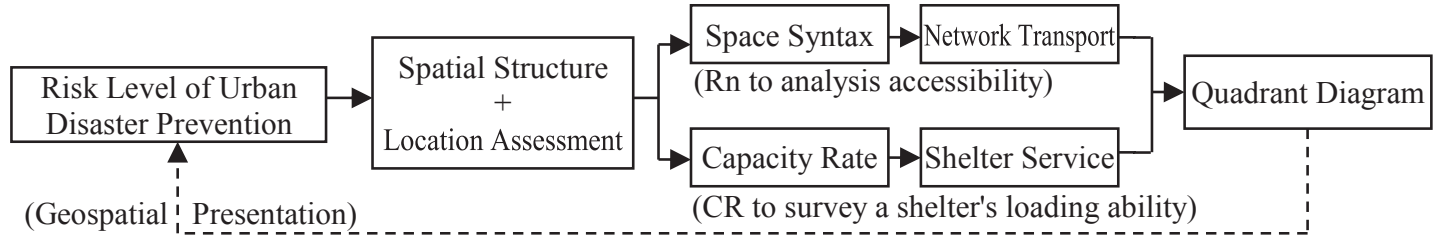

Figure 3. Framework of this research

\subsection{Space Syntax for network transport analysis}

On the basis of the ideas and procedures for understanding spatial topology, space syntax analysis has been used to examine the influence of spatial configuration on human behavior and analyze the factors important for ensuring the accessibility and efficacy of the route network in spatial configuration [12]. Ji-Soo Lee and Won-Hwa Hong reported some characteristics in temporary disaster relief facilities by using an integration ( $\mathrm{Rn})$ indicator [13]. Rn as a tool for measuring the level of accessibility to a movement potential or how easy it is to get to a segment from other segments [14]. The comparative value representing the accessibility of location was obtained by comparing the mean values of the shortest route (i.e., relative depth) from one unit to another in the road system. A high value of Rn for a unit indicates a highly accessible location, implying that the location of that unit is highly efficient and accessible in the road system [15].

The highly accessible route is the core section of topology in an urban route system that reaches the other roads with the fewest corners. In the "Depth Map" software used for space syntax analysis, higher and lower accessibility are indicated by red and blue, respectively (Figure 4). Details of the formula are as follows:

Formula: $R n=1 / R R A ; R R A=R A / D K$

$R n:$ Relative accessibility of whole district

RRA : Real comparative value of asymmetry

$R A:$ Value of asymmetry $=2(d-1) / k-2$

$D K$ : Assumption of the relative depth of symmetry

$d$ : Mean relative depth of the location

$k$ : Number of units, $n-1$
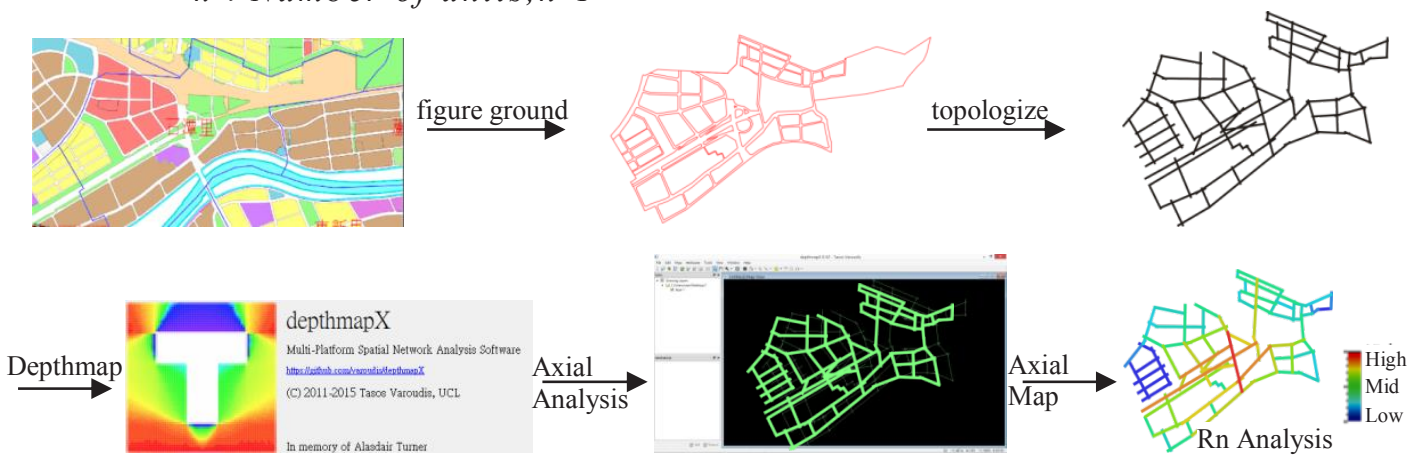

Figure 4. The analysis process in Depthmap X software. 


\subsection{Capacity rate for emergency shelter service survey}

Evacuation routes and centers must be designated and preliminary shelters must be distributed during the short-term aftermath. There must be provisions for traffic control, maintenance of public order, and restriction of access to dangerous areas or places where emergency personnel are working [4]. Therefore, surveying the loading of capacity rate in every emergency shelter can determine whether the emergency shelters cover the service area [16]. In this study, we invested the percentage of capacity rate from a shelter and developed an indicator "CR" to determine the loading ability of shelters. In the formula, the denominator is the total number of people in a locality or village, and the numerator is the number of people a shelter can accommodate in an emergency. The formula is given as follows:

$$
\begin{aligned}
& \text { Formula: } C R \quad \text { (Capacity Rate) }=A P A / T P A \\
& \qquad A P A: \text { acceptable maximum people amount of a shelter's capacity } \\
& \text { TPA : total people amount of a shelter's service cover area }
\end{aligned}
$$

\subsection{Quadrant diagram of performance evaluation in hazard risk}

In this study, we considered a quadrant diagram that divides the background into four parts. The $\mathrm{X}$ axis ( $\mathrm{Rn}$ indicator) and $\mathrm{Y}$-axis ( $\mathrm{CR}$ indicator) were used to draw data that contained two measurements. The measurement target was specified to facilitate environmental investigation using the quadrant diagram as a hazard measurement tool (Figure 5). In disaster management, the quadrant diagram is commonly used as a statistical method because the quadrant pattern represents the integration of two measurement definitions. Thus, if both the measured indicators are higher than the average then they can be defined in the first quadrant, which is the region with the highest spatial efficiency. Broadly, we can define the relatively low-risk region as the first quadrant, and the mediumrisk region as the second and fourth quadrants. If one of $\mathrm{Rn}$ or $\mathrm{CR}$ is above the average then the risk can be defined in the second or fourth quadrant, which are areas with high spatial efficiency. However, if both of the measured indicators are below the average then the risk can be defined in the third quadrant, which is the area with the lowest spatial efficiency. Although disasters occur unpredictably, we must reconsider resource allocation and safety management in the areas of the third quadrant because they are at high risk relative to the overall urban system.

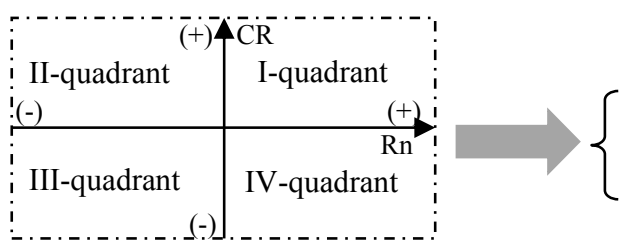

$\left\{\begin{array}{l}\text { Hazard Level : } \\ \text { Low Risk Area(Rn+ and } \mathrm{CR}+): \text { I-quadrant } \\ \text { Middle Rsik Area(Rn+ or } \mathrm{CR}+): \text { I I 、 I V -quadrant } \\ \text { High Risk Area(Rn- and CR-) : I I I -quadrant }\end{array}\right.$

Figure 5. Quadrant diagram depicting hazard levels.

\section{Empirical case study analysis}

From a methodological point of view, this study translated a conceptual disaster prevention schema, an organizational urban infrastructure, and complex spatial relationships into quantitative spatial hazard metrics. Moreover, the study compared various real environmental configurations for different districts and cities. The method and conceptual framework described here can be applied to understanding the differences in disaster management decision making in urban networks. In Japan, the city governments have planned several disaster prevention mechanisms, as is the case in other East Asian countries such as Taiwan. In this study, empirical analysis of two similar urban regions was conducted and the quadrant diagram was developed. On the basis of space syntax and capacity rate, the $\mathrm{Rn}$ and $\mathrm{CR}$ indicators were used to evaluate the accessibility and efficacy of evacuation routes and service performance of shelters. In addition, Neihu and Sumida districts were chosen for the case 
study and compared based on the same environment characteristics, including old communities and new business districts, organic street shapes, and geometric boulevards. The differences between hazard risks and their influence on human behavior toward disaster management were the important concerns addressed in this research. Furthermore, using this information to support decision making for urban resilience and city governance was studied.

\subsection{Rn indicator in Space Syntax case study of Neihu and Sumida districts}

In this section, the routes in Neihu and Sumida districts were evaluated according to the Rn indicator. First, we found some obvious topological differences in the spatial configuration by using space syntax. In the case of Neihu District, the new regions had recently been developed and their topology was geometric. Space syntax proved that the distribution of the routes with high integration was concentrated. However, the old regions had been developed earlier and their topology was organic. Any road system with low integration should be allocated alternate disaster prevention plans to keep its roads useful in case of emergency.

By contrast, in Sumida District, the routes in old regions were highly integrated and concentrated in the topology of the spatial pattern. A ranking methodology using Rn as an indicator shows the maximum efficiency and integrated area in an urban system, and also presents the low-interactivity spots. Thus, the Rn indicator is a powerful indicator to describe the topology and spatial cognition of network configuration(Figure 6). Thus, this research studied the similar urban spaces of Neihu District in Taipei and Sumida District in Tokyo based on the properties of Rn and decoded some patterns for urban planners or decision makers as follows:

(1) The Rn indicator was used to determine the geometric characteristics in the new areas of these two districts; however, the results were not the same. The metrics in Neihu had some straight routes that provided an organized direction for evacuation. However, in Sumida, the central roads (red lines in the space syntax axial map) with high Rn values controlled the old area as a hierarchical network by which the residents or government might be aware of the location of important paths.

(2) The most efficient configuration of the road network was not in the old areas of these two districts because the several turns decreased the connectivity of the networks.

Therefore, in this study, we used the superiority of the Rn indicator as a metric to identify the location of high- or low-transport effectiveness areas. We calculated every path in a neighborhood or village as a unit for comparison with others. There were 39 units in Neihu (Table 3)and 26 units in Sumida(Table 4) to fit in the quadrant diagram. We calculated the average values as a mean index to identify the high- and low-efficacy areas. The low-efficacy area has high risk because it provides low transport effectiveness for people to evacuate, which is not favorable for urban disaster prevention plans [17]. The mean $\mathrm{Rn}$ indicator was $\mathrm{Rn}=1.080$ in Neihu and $\mathrm{Rn}=1.249$ in Sumida. This paper used $\mathrm{Rn}$ as the $\mathrm{X}$-dimension to classify the higher or lower quantities in the case studies.

Table 3. Rn indicator of Neihu District

\begin{tabular}{lllllllll}
\hline No. & Rn(average) & Segments & No. & Rn(average) & Segments & No. & Rn(average) & Segments \\
\hline 1 & 1.264 & 53 & 14 & 0.731 & 101 & 27 & 1.191 & 162 \\
2 & 0.897 & 105 & 15 & 1.02 & 68 & 28 & 1.281 & 58 \\
3 & 0.845 & 95 & 16 & 1.017 & 65 & 29 & 1.208 & 118 \\
4 & 1.377 & 44 & 17 & 1.132 & 40 & 30 & 1.012 & 52 \\
5 & 1.374 & 33 & 18 & 1.188 & 50 & 31 & 0.944 & 55 \\
6 & 1.267 & 69 & 19 & 1.289 & 42 & 32 & 0.753 & 85 \\
7 & 1.159 & 65 & 20 & 1.347 & 13 & 33 & 1.083 & 61 \\
8 & 1.256 & 25 & 21 & 1.055 & 48 & 34 & 0.917 & 79 \\
9 & 1.022 & 57 & 22 & 1.122 & 52 & 35 & 1.09 & 27 \\
10 & 1.001 & 42 & 23 & 0.996 & 30 & 36 & 0.967 & 75 \\
11 & 0.754 & 81 & 24 & 0.711 & 79 & 37 & 1.391 & 33 \\
12 & 1.053 & 40 & 25 & 1.259 & 43 & 38 & 1.163 & 87 \\
13 & 0.681 & 130 & 26 & 1.175 & 31 & 39 & 1.117 & 53 \\
\hline
\end{tabular}




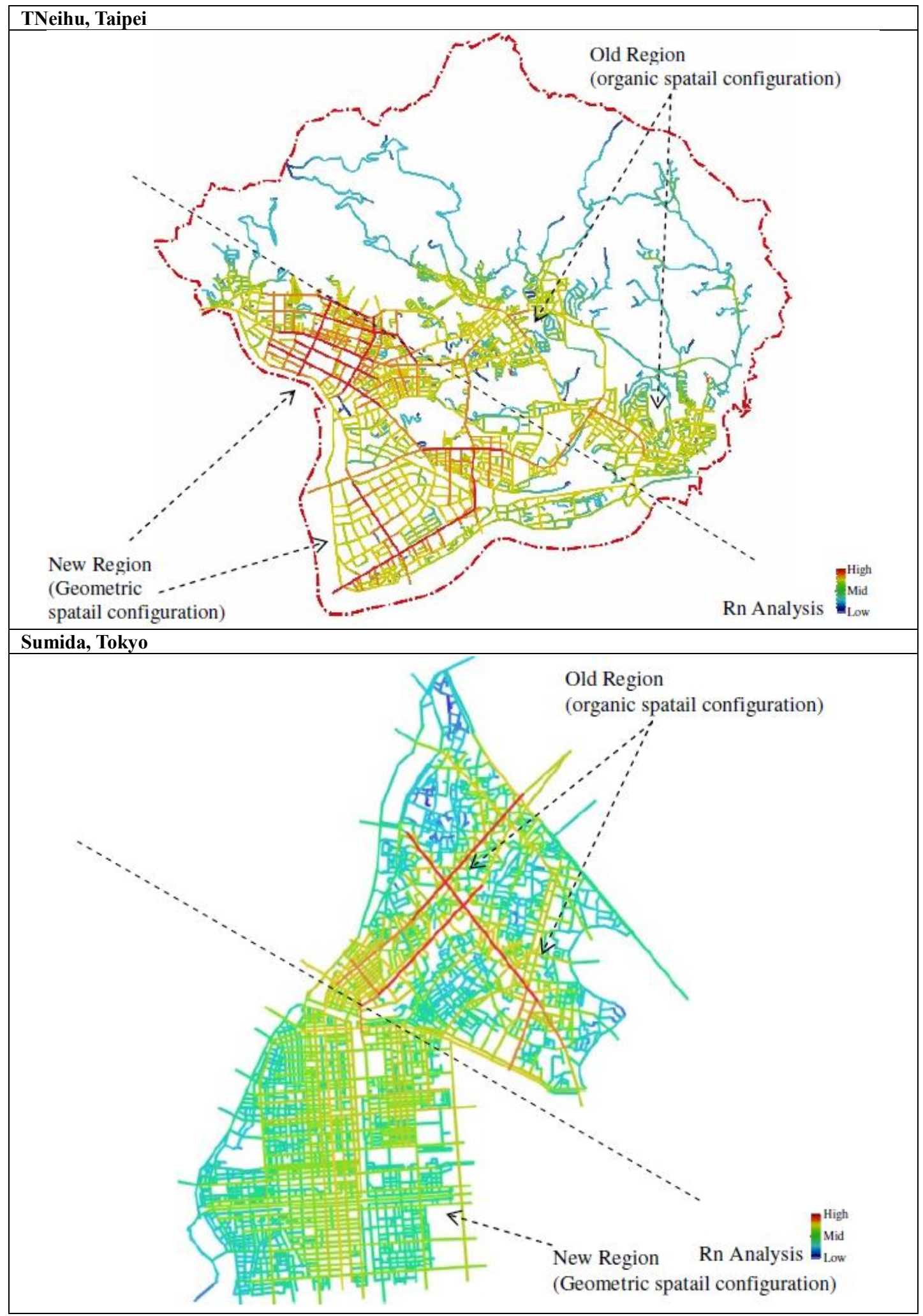

Figure 6. Axial analysis mapping of Neihu and Sumida districts by Space Syntax. 
Table 4. Rn indicator of Sumida District

\begin{tabular}{lllllllll}
\hline No. & Rn(average) & Segments & No. & Rn(average) & Segments & No. & Rn(average) & Segments \\
\hline 1 & 1.161 & 88 & 10 & 1.258 & 79 & 19 & 1.08 & 59 \\
2 & 1.182 & 35 & 11 & 1.278 & 50 & 20 & 1.002 & 200 \\
3 & 1.291 & 63 & 12 & 1.349 & 38 & 21 & 1.298 & 102 \\
4 & 1.328 & 27 & 13 & 1.238 & 23 & 22 & 1.247 & 151 \\
5 & 1.307 & 26 & 14 & 1.337 & 27 & 23 & 1.313 & 85 \\
6 & 1.182 & 37 & 15 & 1.334 & 39 & 24 & 1.217 & 343 \\
7 & 1.114 & 38 & 16 & 1.392 & 48 & 25 & 1.186 & 260 \\
8 & 1.283 & 54 & 17 & 1.396 & 160 & 26 & 1.155 & 93 \\
9 & 1.276 & 72 & 18 & 1.261 & 446 & & & \\
\hline
\end{tabular}

\subsection{CR indicator in capacity rate case study of Neihu and Sumida districts}

In addition to transportation, the real environmental factors, such as the shelters and their capacities, must be considered. After classifying the degree of Rn indicator in Neihu and Sumida, we studied the capacity requirement to ensure the ability of shelters. For example, if people evacuate as fast as possible but there are few shelters with sufficient space, the disaster prevention plans cannot be efficient. Therefore, we surveyed the shelters' capacity and transferred a measurement metric called "CR" to determine the capacity of the shelters. In this section, we use an objective measure of capacity to investigate the shelters and understand the urban resilience of infrastructure during disaster response operations.

This paper calculated the capacity of each shelter (CR indicator) in a neighborhood or village as a unit for comparison with other shelters. We obtained $39 \mathrm{CR}$ values in Neihu (Table 5)and 26 values in Sumida(Table 6) to fit in the quadrant diagram. This paper used the average value as a mean index to identify the high and low efficacy areas. The mean CR indicator was CR $=1.36 \%$ in Neihu and $\mathrm{CR}=$ $21.93 \%$ in Sumida. Moreover, we found some interesting differences between the management of cities and government, including the quality of public facilities and services. These findings were as follows:

(1) The service capacity of the emergency shelters in Sumida was 16 times higher than that in Neihu. This finding indicates the service level of public infrastructure between different cities or countries. Although this may not be a problem in urban planning and disaster prevention plans, it is a safety consideration to provide sufficient shelters or more capacity for disaster prevention and risk control [18].

(2) With respect to the correlation between residents and the shelters' capacity, the survey indicated a higher correlation in Sumida District $\left(R^{2}=0.0491\right)$ than in Neihu $\left(R^{2}=0.0101\right)$ considering similar population (the population is 287,760 in Neihu and 266,356 in Sumida). The survey also presents another way to complement urban resilience or disaster response resolution in case of severe disasters such as earthquakes.

Table 5. CR indicator of Neihu District

\begin{tabular}{llllllllllll}
\hline No. & TPA & APA & CR(\%) & No. & TPA & APA & CR(\%) & No. & TPA & APA & CR(\%) \\
\hline 1 & 7541 & 81 & 1.08 & 14 & 7295 & 52 & 0.71 & 27 & 4014 & 31 & 0.76 \\
2 & 9651 & 100 & 1.04 & 15 & 6221 & 85 & 1.37 & 28 & 9002 & 149 & 1.65 \\
3 & 6869 & 71 & 1.04 & 16 & 8813 & 130 & 1.47 & 29 & 5706 & 94 & 1.65 \\
4 & 6441 & 128 & 1.99 & 17 & 7900 & 181 & 2.29 & 30 & 8387 & 111 & 1.32 \\
5 & 5995 & 197 & 3.29 & 18 & 8464 & 139 & 1.65 & 31 & 6541 & 77 & 1.18 \\
6 & 10063 & 105 & 1.04 & 19 & 8089 & 129 & 1.60 & 32 & 5832 & 52 & 0.90 \\
7 & 9744 & 157 & 1.62 & 20 & 4801 & 71 & 1.48 & 33 & 10485 & 244 & 2.33 \\
8 & 6104 & 50 & 0.83 & 21 & 11990 & 180 & 1.50 & 34 & 9651 & 134 & 1.39 \\
9 & 8605 & 71 & 0.83 & 22 & 8153 & 73 & 0.90 & 35 & 5997 & 84 & 1.39 \\
10 & 8360 & 114 & 1.37 & 23 & 9258 & 83 & 0.90 & 36 & 1406 & 16 & 1.17 \\
11 & 5757 & 68 & 1.18 & 24 & 5044 & 52 & 1.04 & 37 & 6410 & 151 & 2.36 \\
\hline
\end{tabular}




\begin{tabular}{llllllllllll}
\hline 12 & 5572 & 46 & 0.83 & 25 & 8263 & 79 & 0.96 & 38 & 8995 & 145 & 1.61 \\
13 & 7091 & 52 & 0.74 & 26 & 7025 & 67 & 0.96 & 39 & 6225 & 112 & 1.81 \\
\hline
\end{tabular}

Table 6. CR indicator of Sumida District

\begin{tabular}{llllllllllll}
\hline No. & TPA & APA & CR(\%) & No. & TPA & APA & CR(\%) & No. & TPA & APA & CR(\%) \\
\hline 1 & 7268 & 909 & 12.51 & 10 & 8749 & 1425 & 16.29 & 19 & 6707 & 4866 & 72.56 \\
2 & 4526 & 566 & 12.51 & 11 & 6625 & 1450 & 21.89 & 20 & 18213 & 5696 & 31.27 \\
3 & 12948 & 1246 & 9.62 & 12 & 5129 & 1123 & 21.89 & 21 & 10405 & 1841 & 17.69 \\
4 & 5676 & 674 & 11.87 & 13 & 5156 & 552 & 10.71 & 22 & 13141 & 3794 & 28.87 \\
5 & 7537 & 895 & 11.87 & 14 & 11022 & 1267 & 11.50 & 23 & 10737 & 2671 & 24.88 \\
6 & 10122 & 777 & 7.68 & 15 & 8136 & 999 & 12.28 & 24 & 22006 & 5304 & 24.10 \\
7 & 1544 & 190 & 12.28 & 16 & 9840 & 1322 & 13.43 & 25 & 20693 & 8249 & 39.86 \\
8 & 8364 & 3123 & 37.34 & 17 & 15315 & 3758 & 24.54 & 26 & 2295 & 492 & 21.42 \\
9 & 10264 & 3832 & 37.34 & 18 & 23938 & 5908 & 24.68 & & & & \\
\hline
\end{tabular}

\subsection{Hidden differences between hazard risks using quadrant diagram}

We combined the two aforementioned indicators(Figure 7 and 8) and created a hazard map with geographic and disaster risk information that can be used as a rating for the 4th priority of the Sendai Framework for Disaster Risk Reduction. This hazard map can be used as a basis for an increase in disaster management capacity or resource allocation in future. Ultimately, we hope to enrich the 4th priority of the Sendai Framework for Disaster Risk Reduction by using a quantified indicator for disaster management and resilience. Using this assessment method, the following conclusions can be drawn regarding urban governance:

(1) For the low risk area, the spatial networks in Neihu were linear; however, Sumida was separated into two cores, both located in the old and new regions. Thus, in Neihu(Figure 9), only the new region had efficient evacuation ability, whereas in Sumida(Figure 10), the ability was balanced in both the old and new regions.

(2) For the high risk area, two districts with the same result were located at the bordering area. Although it is based on different geographical environments, it can be explained by a simple factor. Any land close to urban zoning and human activities with high land use requires more infrastructure such as effective routes or public open spaces. The high risk area is a residential and business hot spot, with low disaster prevention preparedness.

(3) The efficacy patterns in the old and new regions or organic and geometric spatial configurations were studied. There was no fixed or correct solution for the urban disaster prevention plans. This also provided another viewpoint on the theory of modern urban planning.

(4) The reasons or causes that make these area present high or low risk in Figure 9 and 10 is the important issue for urban planning and disaster prevention policy. And this research spots the high risk area of villages in Neihu and Sumida with the same spatial character through hazard quadrant diagram and risk mapping. In Neihu of Taipei, the high risk area are located nearby the hills and mountains that make the low efficient of accessibility with curved roads (the $\mathrm{Rn}$ indicator is $0.681 \sim 0.753$ and the average is 1.080). Of course, the service radius of shelters nearby hills and mountains are much longer than others and lead to low capacity rate ( the CR indicator is $0.71 \sim 0.83$ and the average is 1.36 ). Identically, in Sumida of Tokyo, the high risk area are located the edge of a district and closed to rivers to cause low efficient of accessibility with blind alley (the $\mathrm{Rn}$ indicator is $1.002 \sim 1.161$ and the average is 1.249). And these area are also earlier-development communities with crowded people but less land for public facilities. This reason caused the low capacity rate, too ( the CR indicator is 12.51 10.71 and the average is 21.96). This research addressed a particular and useful methodology to recognize the service level of urban disaster prevention planning for evacuation roads and shelters. 


\section{IMETI 2017}

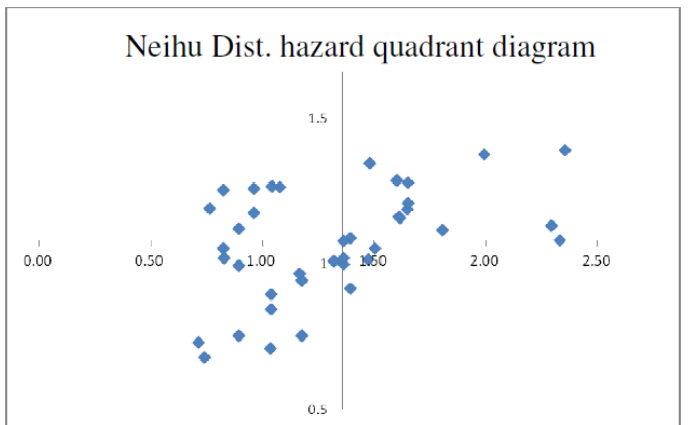

Figure 7. Quadrant Diagram of Neihu District

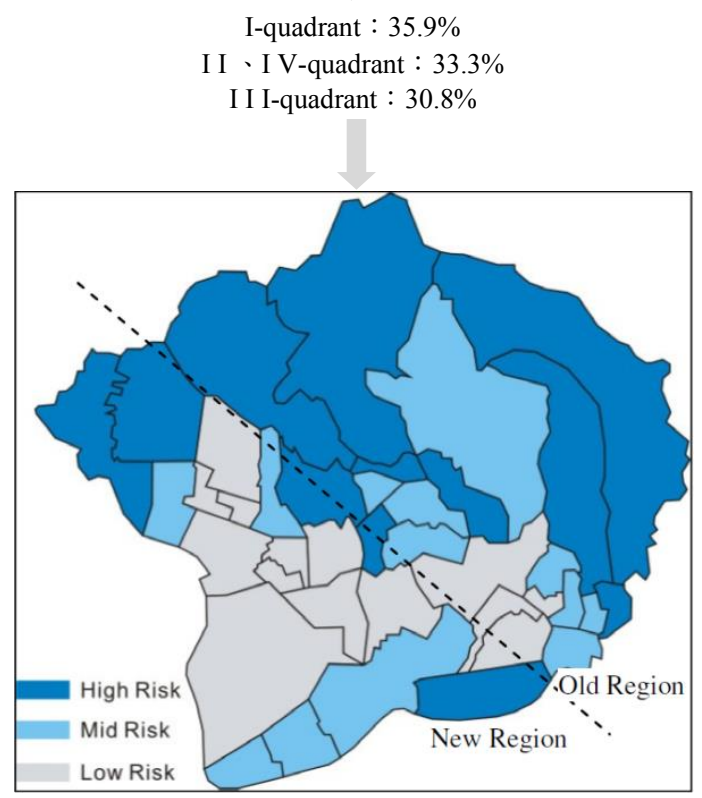

Figure 9. Hazard risk mapping of Neihu District

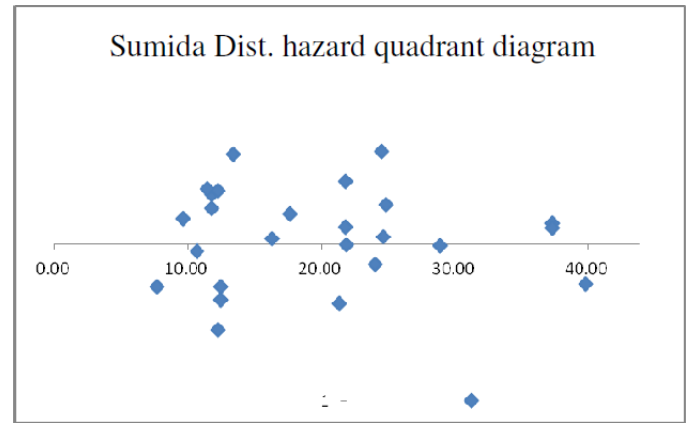

Figure 8. Quadrant Diagram of Sumida District

I-quadrant : $19.2 \%$

I I 、 I V-quadrant : $57.7 \%$

I I I-quadrant : $23.1 \%$

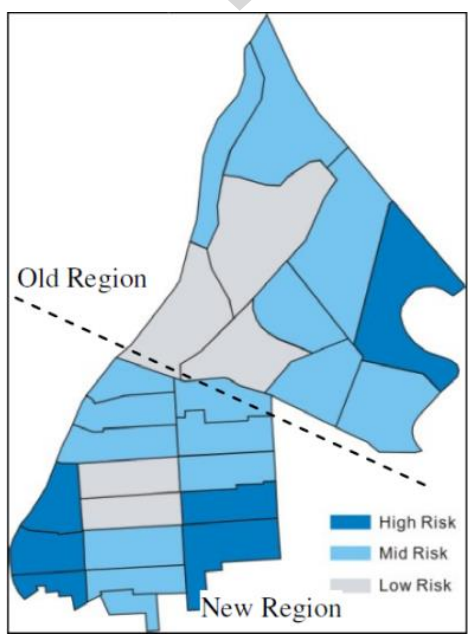

Figure 10. Hazard risk mapping of Sumida District

\subsection{Discussion}

The quadrant diagram is a strategic step and layout for implementing the Sendai Framework for Disaster Risk Reduction. This paper aims to propose a specific assessment method that is feasible and integrated in the 4th priority for action of the Sendai Framework for Disaster Risk Reduction. The proposed method is feasible and reliable and is not necessarily the only reference for the 4th priority. However, we hope to obtain some innovative research results to transform and enhance the disaster preparedness and social security of cities. Through a comprehensive risk survey of the urban road network and emergency shelters, we found some risks that had not been encountered before. This is also a good basis for action regarding the 4th priority, which is expected to lead other researchers to focus on the 4th priority, and enrich and complete the entire disaster reduction program. Thus, this paper presents an empirical study to report a new and innovative assessment methodology for the 4th priority. Moreover, this paper provides a comprehensive indicator for rapid risk assessment and diagnosing risk factors for the 4th priority under limited government resources and public infrastructure. Through this assessment method, we hope to establish a geographic hazard information 
tool to guide the government and disaster management units to adjust or review the urban planning mechanism, and thus provide a more comprehensive urban safety network.

Through this research, we suggest government, urban planners and scholars to rethink the original value of disaster prevention planning. Not only making disaster prevention policies but also modifying regular with quantitative analysis methodology. In these high risk area of this research, we also want to present government to add or build more emergency shelters in parks or open space. On the other hand, the new building permits should be requested to plan evacuation plans for public safety. Like large development plans and reconstruction projects, the evacuation shelters have to be added in first floor of sites to create public contribution to society. Of course, these evacuation shelters have to connect to important roads and lane in urban disaster prevention plans according to Space Syntax analysis.

\section{Conclusion}

Disasters have become an important urban problem because of their unpredictability and heavy casualties in the event of a disaster. For any country and city, people's security and social stability is a basic task and requirement. Even with large amounts of human resources or social costs, it is difficult to completely prevent a disaster. Although there is no solution to this problem, disaster prevention can be improved by using the 4th priority of the Sendai Framework for Disaster Risk Reduction. This paper reveals the hidden risks in cities and decodes the correlation factors, in addition to providing a scientifically quantifiable solution to the qualitative problem of disaster management.

This paper presents a hazard management method that recognizes the urban network patterns and is useful for promoting or upgrading the disaster prevention plans. In future studies, we intend to expand the study to other public facility problems. In addition to urban road networks and emergency shelters, we incorporate a comprehensive survey of other disaster prevention space systems to facilitate the spatial construction for a more safe urban resilience. This paper contributes to the implementation of the 4th priority and other human behaviors or evacuation studies. Moreover, we intend to study human behaviors and asylum to facilitate the implementation of the 4th and other priorities of the Sendai Framework for Disaster Risk Reduction and contribute to the qualitative and quantitative study of disaster management.

\section{References}

1. UNISDR, Sendai Framework for Disaster Risk Reduction 2015-2030, Third UN World Conference on Disaster Risk Reduction (2015)

2. V. Jetel, 8th International Scientific Conference Building Defects, MATEC Web of Conferences, 93, 03009 (2017)

3. B. Zhou, 13th Global Congress on Manufacturing and Management, MATEC Web Conference 100, 02062 (2017)

4. D. Alexander, Dunedin Academic Press, 150, 180-183 (2002)

5. W.Y. Lee, S.T. Chien and S.H. Lee, The Plans on Disaster Prevention System of Urban Planning in Taipei City, The Department of Urban Development of Taipei City Government (1997)

6. W.Y. Lee and M.J. Ho, The Handbook of Disaster Prevention in Urban Planning, Architecture and Building Research Institute of Ministry of the Interior, Taiwan (2000)

7. W.Y. Lee, To Study the Correlation and Spatial Planning of Rescue Locations and Prevention Routes in Central Area of Taipei City, The Department of Urban Development of Taipei City Government (2001)

8. K.A. Adebiyi, O.E Charles- Owaba and M.A. Waheed, Disaster Prevention and Management: An International Journal, 16(2), 178-187 (2007)

9. J. Liu, D. Wu, F. Hidetosi and W. Gao, Open Journal of Civil Engineering, 5, 97-108 (2015)

10. H.S. Chang and C.H. Liao, Nat Hazards, 76, 1551-1571 (2015) 
11. C.H. Liao and H.S. Chang, 3rd International Conference on Environmental Science and Information Application Technology, Procedia Environmental Sciences, 10, 1092-1097 (2011)

12. J.B. Sheu and C. Pen, Transportmetrica A: Transport Science, 11(3), 210-242 (2015)

13. J.S. Lee and W.H. Hong, Human and Ecological Risk Assessment: An International Journal, 21(6), 1968-200 (2015)

14. B. Hillier and T. Stonor, City Planning Institute of Japan, Special Issue : Future of Urban Space and Humanity, 284-288 (2010)

15. B. Jiang and I. Omer, Transactions in GIS, 11(6), 943-960 (2007)

16. F.T. Lin, 23rd International Fire Chiefs' Association of Asia General Conference, Taipei, Taiwan (2004)

17. Transportation Research Board Washington, D.C., The Role of Transit in Emergency Evacuation, Committee on the Role of Public Transportation in Emergency Evacuation, Special Report 294, 43-73 (2008)

18. F. Kilci, B.Y. Kara and B. Bozkaya, European Journal of Operational Research, 243(1), 323-332 (2015) 